\title{
Association between heme oxygenase-1 gene promoter polymorphisms and cancer susceptibility: A meta-analysis
}

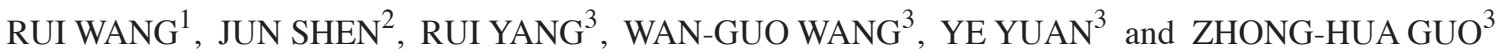 \\ ${ }^{1}$ Department of Nephrology, Renmin Hospital of Wuhan University, Wuhan, Hubei 430060; \\ ${ }^{2}$ Department of Cardiology, Renmin Hospital, Hubei University of Medicine Shiyan, Hubei 442000; \\ ${ }^{3}$ Department of Orthopedics, People's Hospital of Dongxihu District, Wuhan, Hubei 430040, P.R. China
}

Received June 9, 2017; Accepted November 6, 2017

DOI: $10.3892 / b r .2018 .1048$

\begin{abstract}
Numerous studies have focused on the association between heme oxygenase-1 (HO-1) gene promoter polymorphisms and susceptibility to cancer; however, results remain ambiguous. The present systematic Human Genome Epidemiology review and meta-analysis aimed to clarify this association. A systematic search was used to assess the association of HO-1 gene polymorphisms with cancer susceptibility in the PubMed, Web of Science, Cochrane Library, Wanfang Data and China National Knowledge Infrastructure databases, with all reviewed studies published before April 10, 2017. Review Manager 5.3 and Stata 12.0 software were used to perform the meta-analysis. A total of 14 studies were included in the analysis. Overall, no significant associations of the HO-1 (GT)n and T(-413)A polymorphisms with cancer susceptibility were identified. However, subgroup analyses by ethnicity and cancer type indicated that the LL and L-allele (LL+LS) genotypes of HO-1 (GT)n were associated with increased susceptibility to cancer compared with the SS+SL and SS genotypes in the following subgroups: East Asian $[\mathrm{LL}+\mathrm{LS}$ vs. SS: odds ratio $(\mathrm{OR})=1.51,95 \%$ confidence interval $(\mathrm{CI})=1.11-2.05, \mathrm{P}=0.0003$; $\mathrm{LL}$ vs. $\mathrm{SS}+\mathrm{SL}$ : $\mathrm{OR}=1.44$, 95\% CI=1.04-2.01, $\mathrm{P}=0.03$; LL vs. $\mathrm{SS}: \mathrm{OR}=1.64,95 \% \mathrm{CI}=1.07-$ 2.52, $\mathrm{P}=0.02$ ]; squamous cell carcinoma (LL+LS vs. SS: $\mathrm{OR}=1.78,95 \% \mathrm{CI}=1.35-2.34, \mathrm{P}<0.05$; LL vs. $\mathrm{SS}+\mathrm{SL}: \mathrm{OR}=1.71$, 95\% CI=1.34-2.18, P<0.05; LL vs. SS: OR=2.26, 95\% CI $=1.62-3.14, \mathrm{P}<0.05)$; and digestive tract cancer + East Asian (LL+LS vs. $\mathrm{SS}: \mathrm{OR}=1.56,95 \% \mathrm{CI}=1.22-1.98, \mathrm{P}<0.05$; $\mathrm{LL}$ vs. $\mathrm{SS}$ : $\mathrm{OR}=1.80,95 \% \mathrm{CI}=1.06-3.05, \mathrm{P}<0.05)$. These findings indicated that there was no association of the HO-1 (GT)n and T(-413)A polymorphisms with cancer susceptibility, while the L-allele genotypes (LL and LS) of HO-1 (GT)n may be
\end{abstract}

Correspondence to: Dr Zhong-Hua Guo, Department of Orthopedics, People's Hospital of Dongxihu District, 81 Ring Mountain Road, Wuhan, Hubei 430040, P.R. China

E-mail: yarer0@163.com

Key words: cancer, genetics, polymorphism, heme oxygenase-1, meta-analysis susceptibility factors for cancer in East Asian, digestive tract cancer in East Asian and squamous cell carcinoma populations. Due to limitations of the reviewed studies, additional large-scale and refined studies are now required to confirm the present findings.

\section{Introduction}

Cancer has major impacts on public health and the economy in both developing and developed countries (1). In 2012, over 14.1 million new cases of cancer were diagnosed and 8.2 million people succumbed due to cancer worldwide (2). Certain susceptibility factors, including heavy alcohol intake, tobacco use, high calorific diet and chemical dyes, have been identified as potential susceptibility factors for cancer (3). An aging population, increased environmental pollution and longer life expectancy, have also contributed to increased incidence rates of cancer (4). However, the underlying pathogenic mechanisms of cancer remain to be fully elucidated.

Previous studies have indicated that the transition from normal to pre-cancer and cancer cells is a result of a multi-step accumulation of genetic and epigenetic modifications $(5,6)$. Recent studies have focused on the interaction between heme oxygenase-1 (HO-1) gene polymorphisms and cancer $(7,8)$. HO-1 is a subtype of $\mathrm{HO}$, which serves an important role as a rate-limiting enzyme in the conversion of heme into biliverdin, $\mathrm{CO}$ and $\mathrm{Fe}^{2+}(9)$. $\mathrm{HO}-1$ and its products may regulate the levels of reactive oxygen species (ROS) through anti-apoptotic, anti-oxidation, anti-inflammatory effects, and by mediating autophagy (10). In turn, ROS may modulate tumorigenesis by causing cell apoptosis/necrosis or an accumulation of DNA damage (11). Two loci of the HO-1 gene have been focused on when regarding its potential association with cancer, namely the $(\mathrm{GT}) \mathrm{n}$ repeat length polymorphism [which according to repeat length is divided into two classes: $\mathrm{S}$ (short) and L (long)] and T(-413)A (rs2071746) (12-14); however, results so far are not conclusive. Both loci are localized on chromosome 22 q12 and have been identified in the HO-1 gene promoter region (15).

Although numerous studies on the correlation between these two loci and cancer have been conducted, the results are ambiguous (11-14,16,17-29). Based on previous observations, two previous meta-analyses focused on the association of $\mathrm{HO}-1$ 
gene polymorphisms with cancer susceptibility $(30,31)$, though again the data appears inconclusive. Therefore, to clarify the associations between HO-1 gene polymorphisms and cancer susceptibility, an updated meta-analysis was performed in the present study.

\section{Materials and methods}

Protocol. The current meta-analysis was conducted according to the Preferred Reporting Items for Systematic Reviews and Meta-Analyses guidelines (32).

Identification and eligibility of relevant studies. The electronic databases PubMed (https://www.ncbi.nlm.nih. gov/pubmed), Web of Science (http://isiknowledge.com), the Cochrane Library (http://www.cochranelibrary.com/), Wanfang Data (http://www.wanfangdata.com.cn) and China National Knowledge Infrastructure (http://www.cnki.net/) were searched for all studies published before April 10, 2017 that had examined the association between HO-1 gene polymorphisms and cancer. The search strategy was based on combinations of the key words 'heme oxygenase-1 or HMOX1 or HO-1', 'polymorphism or susceptibility' and 'cancer or carcinoma or tumor or malignant or neoplasm'. English or Chinese-language studies were included in the literature search without any special restriction on the source of cases (cancer patients) and controls (normal subjects, free from cancer). Studies in the form of reviews or commentaries and studies in animals or those using cell lines were excluded.

Inclusion criteria. Included studies met the following criteria: i) Case-control study or cohort study; ii) focus on the association of HO-1 (GT)n and T(-413)A polymorphisms with cancer; iii) provision of an odds ratio (OR) with $95 \%$ confidence intervals (CIs) or sufficient data for calculation of OR and 95\% CIs.

Data extraction. The following information were extracted from each eligible study: Name of author, year of publication, ethnicity or geographic location of study subjects, cancer type, study design, genotyping method, cohort age, cohort sex ratio, use of age and sex matching, and consistency of genotype frequencies with Hardy-Weinberg Equilibrium (HWE). Allele and genotype frequencies were extracted or calculated from the published data in the included studies. The bibliographic search and data extraction were carried out by two independent reviewers, and disagreements were resolved by discussion among the reviewers.

Data synthesis and analysis. The meta-analysis was performed using Review Manager 5.3 (http://tech.cochrane. org/revman) and Stata 12.0 software (StataCorp LP, College Station, TX, USA). The $\chi^{2}$ test was applied to verify whether the genotype distribution of the control group in each study conformed to HWE. Four genetic models were used: An allele model (L vs. S); a dominant model (LL vs. SS+SL); a co-dominant model (LL vs. SS); and a recessive model (LL+LS vs. SS). To evaluate sources of heterogeneity across studies, subgroup analyses were conducted based on ethnicity, cancer type, tumor location and HWE. Heterogeneity was determined using $\mathrm{I}^{2}$ statistics; when $\mathrm{I}^{2}<50 \%$, the fixed-effects model was used, while for $\mathrm{I}^{2}>50 \%$, the random-effects model was used and meta-regression analysis was performed to detect the source of heterogeneity. Stratification analyses were performed based on the outcome of meta-regression analysis. Results were determined as ORs with 95\% CIs and P-values. $\mathrm{P}<0.05$ was considered to indicate statistical significance. Sensitivity analyses were conducted by omitting each study in turn and by excluding studies with departure from HWE. Funnel plots and Egger's/Begg's tests were used to visualize the overall effect and to evaluate publication bias, respectively.

\section{Results}

Study characteristics. The systematic literature search identified 206 potentially relevant articles. After excluding duplications, 187 titles and abstracts were screened. A total of 165 articles were excluded due to irrelevance to the aim of the present study. The remaining 22 articles underwent full-text examination, and two studies $(33,34)$ were excluded due to their analysis of the same subjects reported in two different studies $(16,19)$, with the latter studies selected due to their inclusion of more data. Another two studies $(20,35)$ were excluded as genotype data could not be obtained, one study (7) was not a case-control study, and two studies $(8,36)$ used cancer patients in the control group. Thus, 14 studies $(9,13,15,16,18-26)$ were included in the meta-analysis, among which were 12 studies $(9,13,15,16,18-24)$ on (GT)n repeat length polymorphism and three studies $(21,25,26)$ on $\mathrm{T}(-413) \mathrm{A}$ single nucleotide polymorphism (SNP) associations with cancer susceptibility (Table I).

\section{Meta-analysis}

HO- $1(G T) n$ repeat length polymorphism and susceptibility to cancer. The association between the HO-1(GT)n repeat length polymorphism and cancer susceptibility was investigated in 12 relevant studies involving 2,471 patients with cancer and 2,654 normal controls. No significant associations were identified between susceptibility to overall cancer and the SNP in any of the four genetic models screened ( $\mathrm{L} v \mathrm{vs}$. S, LL+LS vs. SS, LL vs. SS+SL, LL vs. SS). However, subgroup analyses by ethnicity and cancer type indicated that the HO-1(GT) $\mathrm{n}$ repeat length polymorphism was associated with cancer susceptibility in the East Asian, squamous cell carcinoma and digestive tract cancer + East Asian subgroups (Table II).

The first subgroup analysis was conducted according to ethnicity. It was identified that the LL and L-allele (LL+LS) genotypes were associated with increased susceptibility to cancer compared with the SS+SL and SS genotypes in the East Asian subgroup (LL+LS vs. SS: OR=1.51, 95\% CI=1.11-2.05, $\mathrm{P}=0.0003$; LL vs. SS+SL: $\mathrm{OR}=1.44$, 95\% $\mathrm{CI}=1.04-2.01$, $\mathrm{P}=0.03$; LL vs. $\mathrm{SS}: \mathrm{OR}=1.64,95 \% \mathrm{CI}=1.07-2.52, \mathrm{P}=0.02$ ). By contrast, no significant associations were identified in the genetic models with non-East Asian (Caucasian, American, West Asian) populations (Table II).

The second subgroup analysis was conducted according to cancer type. It was also identified that patients carrying the LL genotype and L-allele genotypes (LL+LS) had increased susceptibility to squamous cell carcinoma compared with SS+SL and SS genotype carriers (LL+LS vs. SS: $\mathrm{OR}=1.78,95 \% \mathrm{CI}=1.35-2.34, \mathrm{P}<0.0001$; $\mathrm{LL}$ vs. $\mathrm{SS}+\mathrm{SL}$ : $\mathrm{OR}=1.71,95 \% \mathrm{CI}=1.34-2.18, \mathrm{P}<0.0001$; LL vs. $\mathrm{SS}: \mathrm{OR}=2.26$, 


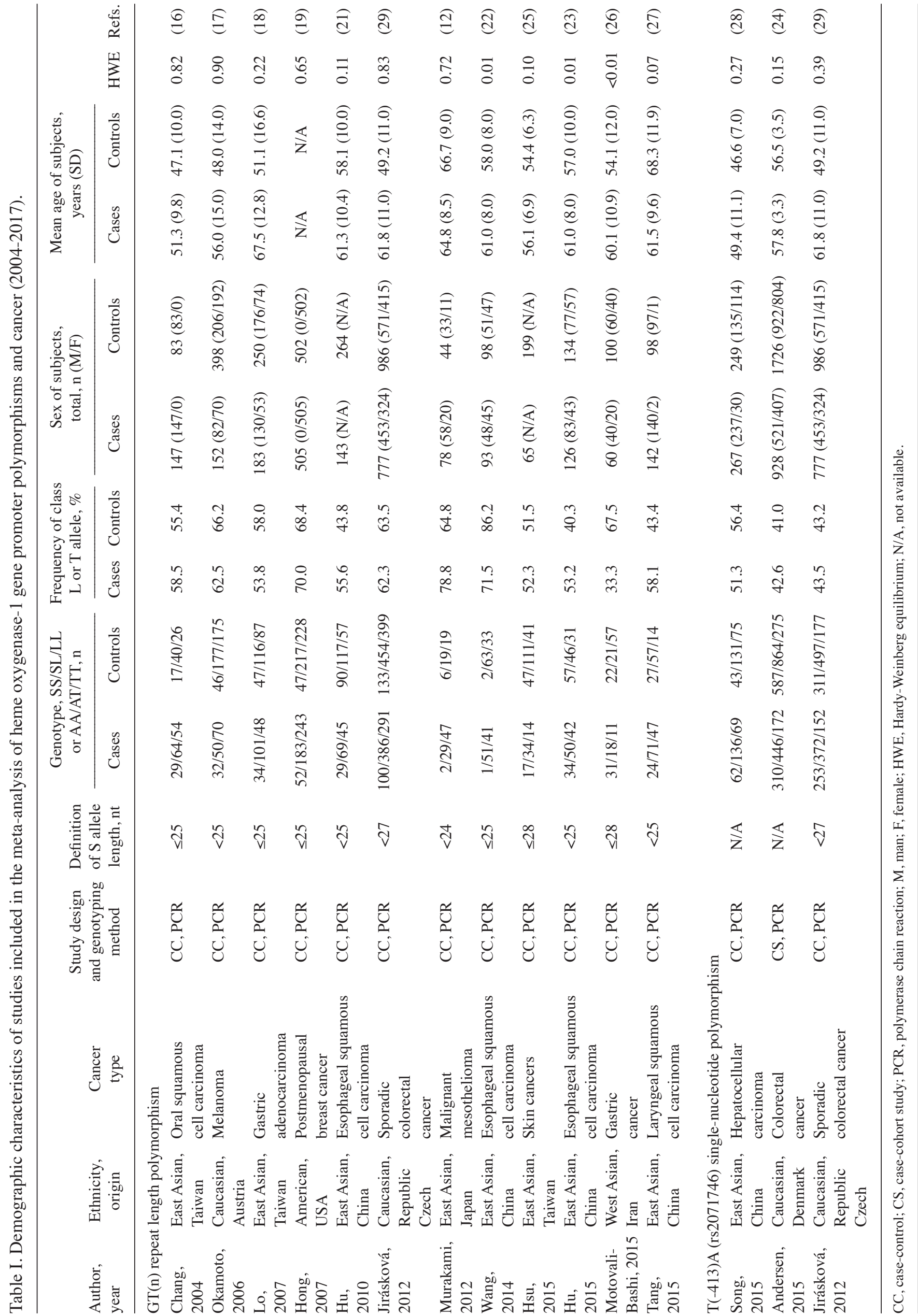




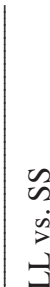

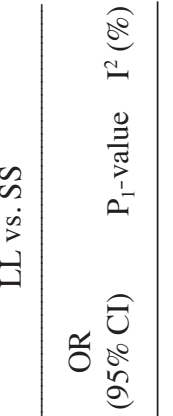

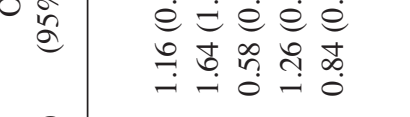

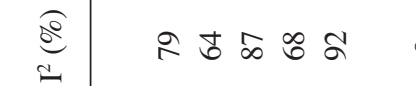

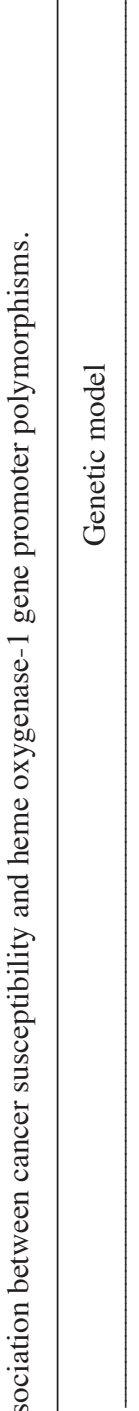

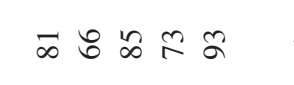

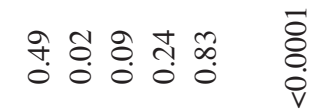

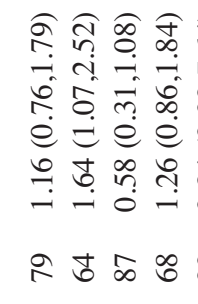

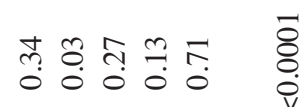

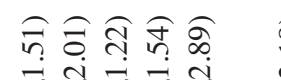

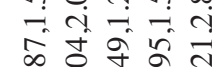

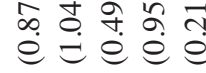

牙寺尽

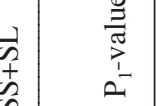

च

产

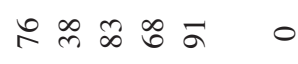

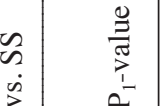

ڤ.

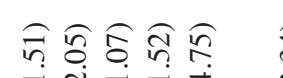

츨 药

$\dot{e}=\stackrel{n}{e} \stackrel{\infty}{e} \vec{e}$

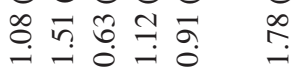

중

ङ

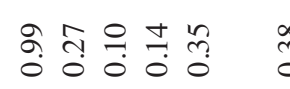

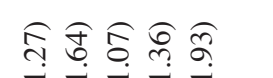

रेक

èeje é

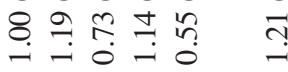

于

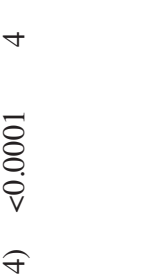

$\begin{array}{lll}\curvearrowleft & 8 & \ddots \\ n\end{array}$

ब

จิ

तु ?ू. हु.

e $=0$

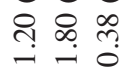

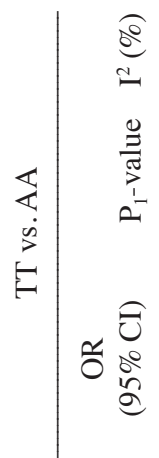

in

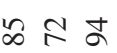

a

$\stackrel{\infty}{0}$

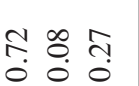

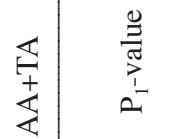

สิิㅡㅇ

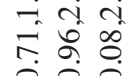

e e e

站 导.

충

$\stackrel{5}{5}$

兽

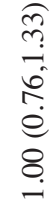

i

กุ่

के के ब

बิ

ปั. \&े ले

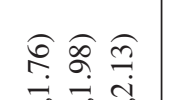

ㄷํำ

$e=$

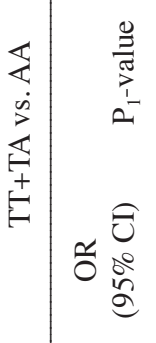

モn

สำ

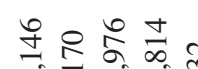

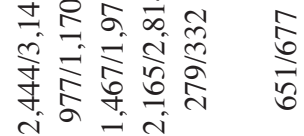

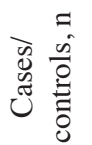

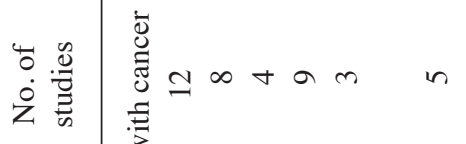

政

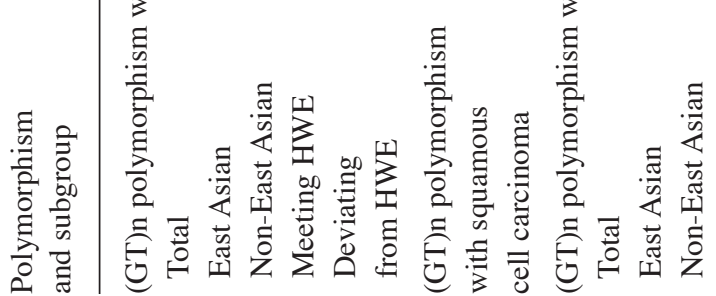

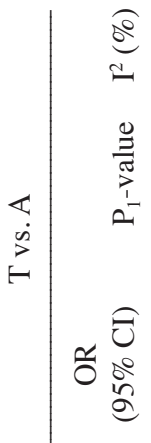

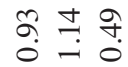

苞

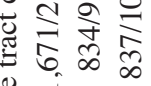

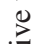

.

$\infty 00$

$\Xi$ 
Table III. Egger's and Begg's test results.

\begin{tabular}{|c|c|c|c|}
\hline Association & Genetic model & $\mathrm{P}_{1}$-value & $\mathrm{P}_{2}$-value \\
\hline \multirow[t]{4}{*}{ (GT)n polymorphism and cancer } & Lvs. S & 0.072 & 0.732 \\
\hline & LL+LS vs. SS & 0.023 & 0.244 \\
\hline & LL vs. SS+SL & 0.744 & 0.631 \\
\hline & LL vs. SS & 0.397 & 0.945 \\
\hline \multirow[t]{4}{*}{ (GT)n polymorphism and squamous cell carcinoma } & Lvs. S & 0.673 & 0.806 \\
\hline & $\mathrm{LL}+\mathrm{LS}$ vs. SS & 0.653 & 0.806 \\
\hline & LL vs. SS+SL & 0.917 & 0.806 \\
\hline & LL vs. SS & 0.691 & 1.000 \\
\hline \multirow[t]{4}{*}{ (GT)n polymorphism and digestive tract cancer } & L vs. S & 0.107 & 1.000 \\
\hline & $\mathrm{LL}+\mathrm{LS}$ vs. SS & 0.024 & 0.386 \\
\hline & LL vs. SS+SL & 0.543 & 0.174 \\
\hline & LL vs. SS & 0.300 & 0.902 \\
\hline \multirow[t]{4}{*}{$\mathrm{T}(-413) \mathrm{A}$ polymorphism and digestive system neoplasms } & T vs. A & 0.491 & 1.000 \\
\hline & TT+TA vs. AA & 0.157 & 1.000 \\
\hline & TT vs. AA+TA & 0.675 & 1.000 \\
\hline & TT vs. AA & 0.285 & 0.296 \\
\hline
\end{tabular}

$\mathrm{P}_{1}$-value, Egger's test result; $\mathrm{P}_{2}$-value, Begg's test result.

95\% $\mathrm{CI}=1.62-3.14, \mathrm{P}<0.0001)$. However, no associations were observed in any of the four allelic genetic models with digestive tract cancer (Table II).

The third subgroup analysis was conducted according to tumor location and ethnicity. It was observed that patients carrying the LL genotype and L-allele genotypes (LL+LS) had increased susceptibility to digestive tract cancer compared with SL+SS and SS genotype carriers in the East Asian subgroup (LL+LS vs. SS: $\mathrm{OR}=1.56,95 \% \mathrm{CI}=1.22-1.98$, $\mathrm{P}=0.003$; LL vs. $\mathrm{SS}$ : $\mathrm{OR}=1.80,95 \% \mathrm{CI}=1.06-3.05, \mathrm{P}=0.03$ ). However, no associations were observed in the allelic and co-dominant genetic models regarding cancer susceptibility in the digestive tract cancer + non-East Asian and squamous cell carcinoma + East Asian/non-East Asian subgroups (Table II).

Subgroup analysis was also conducted according to HWE. No significant associations were identified between susceptibility to overall cancer and HO-1(GT)n in any of the four genetic models for cases that met or deviated from HWE (Table II).

HO-1 T(-413)A SNP and cancer susceptibility. There were 3 studies that investigated the association between the HO-1 T(-413)A SNP and digestive system neoplasms. The metaanalysis suggested that there were no significant associations between the HO-1 T(-413)A polymorphism and overall cancer susceptibility in any of the genetic models (Table II).

Sensitivity analysis. The stability of the results was assessed by sensitivity analyses, which were conducted for all genetic comparisons by omitting each study in turn. It was determined that no study had substantial influence on the pooled ORs in all genetic models, suggesting the results were stable. In addition, the ORs were unaltered by omitting studies in which the genotype distribution in controls departed from HWE.

Publication bias. Funnel plots and Begg's tests were used to evaluate the publication bias of the included studies. From the funnel plots and Begg's tests, no indication of publication bias was identified in the studies on the (GT)n repeat length polymorphism or T(-413)A SNP (Fig. 1 and Table III).

\section{Discussion}

There are three isoforms of $\mathrm{HO}$ in human, namely $\mathrm{HO}-1, \mathrm{HO}-2$ and HO-3 (37). HO-1, also known as heat shock protein 32, is upregulated by a number of chemical and physical stresses (38). Animal experiments have confirmed that HO-1 localizes to endoplasmic reticulum, caveolae, mitochondria and the nucleus, indicating the possibility that $\mathrm{HO}-1$ serves roles in addition to heme degradation (9). HO-1 expression is elevated in a variety of tumors and neoplasms (39). HO-1 and its products may promote tumor growth through anti-apoptotic, anti-oxidation, anti-inflammatory and proliferative effects, and by mediating autophagy (40-42). Thus, HO-1 activity is considered to be conducive to tumor growth (43).

Numerous studies have demonstrated that the LL genotype of the HO-1(GT)n locus may increase cancer susceptibility $(12,13,16,18,19,21)$. However, the associations identified between the HO-1 polymorphisms and cancer susceptibility are inconsistent, and other studies have come to other conclusions $(15,17,26)$. Additionally, two previously published meta-analyses reported different conclusions $(30,31)$. More recently, a number of studies on this topic have been published (19-25). Therefore, the present study conducted an update meta-analysis following different inclusion criteria to that used previously to evaluate the association of HO-1 polymorphisms with cancer susceptibility.

The present meta-analysis indicated that there was no significant association between the HO-1(GT)n repeat length polymorphism and overall cancer susceptibility. However, on subgroup analysis, the LL and L-allele (LL+LS) genotypes of the HO-1(GT)n locus were associated with a higher 

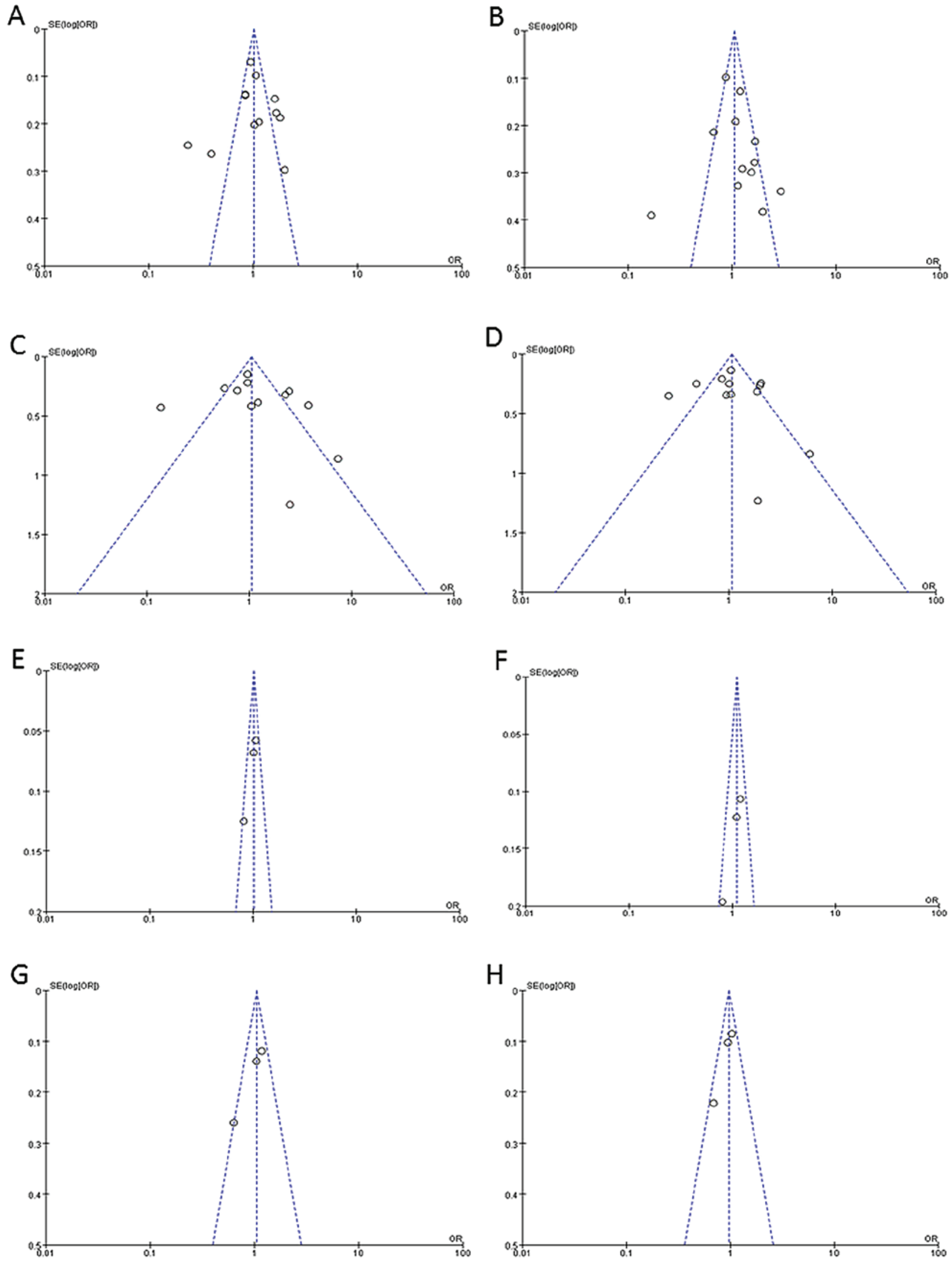

Figure 1. (A-H) Funnel plots representing the association between (GT)n polymorphism in heme oxygenase-1 (HO-1) gene and cancer susceptibility. (A and E) The allele model (L vs. S; T vs. A); (B and F) the dominant model (LL vs. SS+SL; TT vs. AA+AT); (C and G) the co-dominant model (LL vs. SS; TT vs. AA); (D and H) the recessive model (LL+LS vs. SS; TT+AT vs. AA).

susceptibility to squamous cell carcinoma, digestive tract cancer in East Asian carriers and overall cancer in East
Asian carriers compared with the SS and/or SL genotype. By contrast, this association with susceptibility was not 
observed in any of the four genetic models in non-East Asian (Caucasian, American and West Asian) populations. This may be due to differences in life styles, ethnicity, region, cancer type and tumor location, among other factors. The present study also identified no significant associations between the HO-1 T(-413)A SNP and overall cancer susceptibility. These results are consistent with a previous study by Luo et al (31).

However, the present analysis had a number of limitations, as follows: i) The language was restricted to English and Chinese, which excluded eligible studies in other languages; ii) the sample size of included studies on HO-1 T(-413)A SNP was markedly small; iii) the thresholds defined as class $\mathrm{S}$ (short) were not uniform in different studies; iv) to an extent, factors such as differences in age and condition of the patients may have affected the stability of results, though were unavoidable. Collectively, these limitations may have affected the final conclusions.

Nevertheless, the current results indicated that there was no association of the HO-1 (GT)n and T(-413)A polymorphisms with overall cancer susceptibility. However, the L-allele genotypes (LL and LS) may be susceptibility factors for cancer in East Asian, digestive tract cancer in East Asian and squamous cell carcinoma populations. Due to the limitations of the included studies, larger refined studies are now required to confirm these conclusions.

\section{References}

1. Siegel RL, Miller KD and Jemal A: Cancer Statistics, 2017. CA Cancer J Clin 67: 7-30, 2017.

2. Torre LA, Bray F, Siegel RL, Ferlay J, Lortet-Tieulent J and Jemal A: Global cancer statistics, 2012. CA Cancer J Clin 65 87-108, 2015.

3. Verdoodt F, Kjaer Hansen M, Kjaer SK, Pottegård A, Friis S and Dehlendorff C: Statin use and mortality among ovarian cancer patients: A population-based cohort study. Int J Cancer 141: 279-286, 2017.

4. Braga SFM, de Souza MC and Cherchiglia ML: Time trends for prostate cancer mortality in Brazil and its geographic regions: An age-period-cohort analysis. Cancer Epidemiol 50: 53-59, 2017.

5. Coppedè F: Epigenetic biomarkers of colorectal cancer: Focus on DNA methylation. Cancer Lett 342: 238-247, 2014.

6. McCleary-Wheeler AL, Lomberk GA, Weiss FU, Schneider G, Fabbri M, Poshusta TL, Dusetti NJ, Baumgart S, Iovanna JL, Ellenrieder $\mathrm{V}$, et al: Insights into the epigenetic mechanisms controlling pancreatic carcinogenesis. Cancer Lett 328: 212-221, 2013.

7. Wu MM, Lee CH, Hsu LI, Cheng WF, Lee TC, Wang YH, Chiou HY and Chen CJ: Effect of heme oxygenase-1 gene promoter polymorphism on cancer risk by histological subtype: A prospective study in arseniasis-endemic areas in Taiwan. Int $J$ Cancer 138: 1875-1886, 2016.

8. Ghadban T, Miro JT, Trump F, Tsui TY, Uzunoglu FG, Reeh M, Gebauer F, Bachmann K, Wellner U, Kalinin V, et al: Diverse prognostic value of the GTn promoter polymorphism in squamous cell and adeno carcinoma of the oesophagus. Clin Genet 90: 343-350, 2016.

9. Dunn LL, Midwinter RG, Ni J, Hamid HA, Parish CR and Stocker R: New insights into intracellular locations and functions of heme oxygenase-1. Antioxid Redox Signal 20: 1723-1742, 2014.

10. Zhang MM, Zheng YY, Gao Y, Zhang JZ, Liu F, Yang YN, $\mathrm{Li} \mathrm{XM}$, Ma YT and Xie X: Heme oxygenase-1 gene promoter polymorphisms are associated with coronary heart disease and restenosis after percutaneous coronary intervention: A meta-analysis. Oncotarget 7: 83437-83450, 2016.

11. Luo H, Li Z, Qing Y, Zhang SH, Peng Y, Li Q and Wang D: Single nucleotide polymorphisms of DNA base-excision repair genes (APE1, OGG1 and XRCC1) associated with breast cancer risk in a Chinese population. Asian Pac J Cancer Prev 15: $1133-1140,2014$
12. Murakami A, Fujimori Y, Yoshikawa Y, Yamada S, Tamura K, Hirayama N, Terada T, Kuribayashi K, Tabata C, Fukuoka K, et al: Heme oxygenase-1 promoter polymorphism is associated with risk of malignant mesothelioma. Lung 190: 333-337, 2012.

13. Kikuchi A, Yamaya M, Suzuki S, Yasuda H, Kubo H, Nakayama K, Handa M, Sasaki T, Shibahara S, Sekizawa K, et al: Association of susceptibility to the development of lung adenocarcinoma with the heme oxygenase-1 gene promoter polymorphism. Hum Genet 116: 354-360, 2005.

14. Andersen V, Christensen J, Overvad K, Tjønneland A and Vogel U: Heme oxygenase-1 polymorphism is not associated with risk of colorectal cancer: A Danish prospective study. Eur J Gastroenterol Hepatol 23: 282-285, 2011.

15. Kuwano A,Ikeda H, Takeda K, Nakai H, Kondo I and Shibahara S: Mapping of the human gene for inducible heme oxygenase to chromosome 22q12. Tohoku J Exp Med 172: 389-392, 1994.

16. Chang KW, Lee TC, Yeh WI, Chung MY, Liu CJ, Chi LY and Lin SC: Polymorphism in heme oxygenase-1 (HO-1) promoter is related to the risk of oral squamous cell carcinoma occurring on male areca chewers. Br J Cancer 91: 1551-1555, 2004.

17. Okamoto I, Krögler J, Endler G, Kaufmann S, Mustafa S, Exner M, Mannhalter C, Wagner O and Pehamberger H: A microsatellite polymorphism in the heme oxygenase-1 gene promoter is associated with risk for melanoma. Int J Cancer 119: 1312-1315, 2006.

18. Lo SS, Lin SC, Wu CW, Chen JH, Yeh WI, Chung MY and Lui WY: Heme oxygenase-1 gene promoter polymorphism is associated with risk of gastric adenocarcinoma and lymphovascular tumor invasion. Ann Surg Oncol 14: 2250-2256, 2007.

19. Hong CC, Ambrosone CB, Ahn J, Choi JY, McCullough ML, Stevens VL, Rodriguez C, Thun MJ and Calle EE: Genetic variability in iron-related oxidative stress pathways (Nrf2, NQ01, NOS3, and HO-1), iron intake, and risk of postmenopausal breast cancer. Cancer Epidemiol Biomarkers Prev 16: 1784-1794, 2007.

20. Sawa T, Mounawar M, Tatemichi M, Gilibert I, Katoh T and Ohshima H: Increased risk of gastric cancer in Japanese subjects is associated with microsatellite polymorphisms in the heme oxygenase- 1 and the inducible nitric oxide synthase gene promoters. Cancer Lett 269: 78-84, 2008.

21. Hu JL, Li ZY, Liu W, Zhang RG, Li GL, Wang T, Ren JH and Wu G: Polymorphism in heme oxygenase-1 (HO-1) promoter and alcohol are related to the risk of esophageal squamous cell carcinoma on Chinese males. Neoplasma 57: 86-92, 2010.

22. Wang XW, Wang JN, Wang AL, et al: Association study between the risk of esophageal squamous cell carcinoma and microsatellite polymorphism in promoter of heme oxygenase-1. Hebei Mediacl J 5: 668-670, 2014.

23. Hu B, Zhang J, Wang J, Zhu C, Chen B, Kong M, Zhang B and Zhu M: The risk of esophageal squamous cell carcinoma associated with microsatellite polymorphism in promoter of heme oxygenase-1. Zhonghua Wai Ke Za Zhi 53: 206-210, 2015 (In Chinese).

24. Andersen V, Kopp TI, Tjønneland A and Vogel U: No association between HMOX1 and risk of colorectal cancer and no interaction with diet and lifestyle factors in a prospective Danish case-cohort study. Int J Mol Sci 16: 1375-1384, 2015.

25. Hsu LI, Wu MM, Wang YH, Lee CY, Yang TY, Hsiao BY and Chen CJ: Association of environmental arsenic exposure, genetic polymorphisms of susceptible genes, and skin cancers in Taiwan. BioMed Res Int 2015: 892579, 2015.

26. Motovali-Bashi $\mathbf{M}$ and Hamidy $M$ : Association between GT-repeat polymorphism at heme oxygenase-1 gene promoter and gastric cancer and metastasis. Tumour Biol 36: 4757-4762, 2015.

27. Tang D, Tang WJ, Shi XL, Li WP, Zhou H, Lu LM and Tao L: Association of the microsatellite (GT)n repeat polymorphisms of the HO-1 gene promoter and corresponding serum levels with the risk of laryngeal squamous cell carcinoma. Acta Otolaryngol 136: 806-811, 2016.

28. Song LY: Association of heme oxygenase-1 polymorphisms with hepatitis B-related liver disease. Guangxi Med Univ 24: 111-120, 2015.

29. Jirásková A, Novotný J, Novotný L, Vodicka P, Pardini B, Naccarati A, Schwertner HA, Hubácek JA, Puncochárová L, Šmerhovský Z, et al: Association of serum bilirubin and promoter variations in HMOX1 and UGT1A1 genes with sporadic colorectal cancer. Int J Cancer 131: 1549-1555, 2012

30. Zhang L, Song FF, Huang YB, Zheng H, Song FJ and Chen KX: Association between the (GT)n polymorphism of the HO-1 gene promoter region and cancer risk: A meta-analysis. Asian Pac J Cancer Prev 15: 4617-4622, 2014. 
31. Luo H, Shao Y, Yao N, Chen X, Hu L and He T: Association of heme oxygenase-1 polymorphisms with cancer risk: A systematic review and meta-analysis. J BUON 20: 1142-1153, 2015.

32. Moher D, Liberati A, Tetzlaff J and Altman D: Reviews and Meta-Analyses: The PRISMA statement reprint - Preferred reporting items for systematic. Phys Ther 89: 873-880, 2009.

33. Lin SC, Liu CJ, Yeh WI, Lui MT, Chang KW and Chang CS: Functional polymorphism in NFKB1 promoter is related to the risks of oral squamous cell carcinoma occurring on older male areca (betel) chewers. Cancer Lett 243: 47-54, 2006.

34. Li Y, Ambrosone CB, McCullough MJ, Ahn J, Stevens VL, Thun MJ and Hong CC: Oxidative stress-related genotypes, fruit and vegetable consumption and breast cancer risk. Carcinogenesis 30: 777-784, 2009.

35. Ishikawa M, Kajimura M, Adachi T, Maruyama K, Makino N, Goda N, Yamaguchi T, Sekizuka E and Suematsu M: Carbon monoxide from heme oxygenase-2 is a tonic regulator against NO-dependent vasodilatation in the adult rat cerebral microcirculation. Circ Res 97: e104-e114, 2005.

36. Vashist YK, Uzungolu G, Kutup A, Gebauer F, Koenig A, Deutsch L, Zehler O, Busch P, Kalinin V, Izbicki JR, et al: Heme oxygenase-1 germ line GTn promoter polymorphism is an independent prognosticator of tumor recurrence and survival in pancreatic cancer. J Surg Oncol 104: 305-311, 2011.

37. Bouche D, Chauveau C, Roussel JC, Mathieu P, Braudeau C, Tesson L, Soulillou JP, Iyer S, Buelow R and Anegon I: Inhibition of graft arteriosclerosis development in rat aortas following heme oxygenase-1 gene transfer. Transpl Immunol 9: 235-238, 2002.
38. Hadzijusufovic E, Rebuzzi L, Gleixner KV, Ferenc V, Peter B, Kondo R, Gruze A, Kneidinger M, Krauth MT and Mayerhofer M: Targeting of heat-shock protein 32/heme oxygenase-1 in canine mastocytoma cells is associated with reduced growth and induction of apoptosis. Exp Hematol 36: 1461-1470, 2008.

39. Maines MD and Abrahamsson PA: Expression of heme oxygenase-1 (HSP32) in human prostate: Normal, hyperplastic, and tumor tissue distribution. Urology 47: 727-733, 1996.

40. Li YX, Li G, Dong WP, Chen J, Wang YF, Chen XB, Lu DR and Tan JM: Transduction of heme oxygenase-1 gene to human Islet cells via adenovirus vector enhances anti-apoptosis function and insulin release. Zhonghua Yi Xue Za Zhi 86: 915-918, 2006 (In Chinese)

41. Nemeth Z, Li M, Csizmadia E, Döme B, Johansson M, Persson JL, Seth P, Otterbein L and Wegiel B: Heme oxygenase-1 in macrophages controls prostate cancer progression. Oncotarget 6: 33675-33688, 2015.

42. Chau LY: Heme oxygenase-1: Emerging target of cancer therapy. J Biomed Sci 22: 22, 2015.

43. Nitti M, Piras S, Marinari UM, Moretta L, Pronzato MA and Furfaro AL: HO-1 induction in cancer progression: A matter of cell adaptation. Antioxidants 6: 6, 2017.

This work is licensed under a Creative Commons Attribution-NonCommercial-NoDerivatives 4.0 International (CC BY-NC-ND 4.0) License. 